\title{
¿Cuál es la autoridad de los que sufren en mi realidad histórica para la Fe Cristiana y la Teología?
}

\author{
Andrés Fabián Valbuena Henao ${ }^{1}$
}

Recibido: 08-01-2018

Aceptado: 20-03-2018

A continuación, en el presente escrito, se dará respuesta a la pregunta, desde un enfoque totalmente particular y distinto al esperado, puesto que algunas lecturas de Filosofía y Teología de la Liberación², que se han abordado para responder a la pregunta, apuntan, en líneas generales, a corroborar lo que plantea Martha Zechmeister en su intervención, "La Autoridad de los que sufren" ${ }^{\prime 3}$. Para tal caso, la idea a probar es que los que sufren en mi realidad histórica tienen una autoridad testimonial y pericia casuística particular, que no se puede desconocer, sin embargo no tienen autoridad para determinar el último sentido teológico. Por tanto, para desarrollar la idea mencionada, se hará una contextualización, se expondrán aclaraciones del tema del sufrimiento y su relación con la pregunta, se expondrá y explicará con detalle las premisas que configuran la respuesta y se concluirá.

El contexto sociopolítico actual, es el resultado de un proceso de guerras que se dieron en el siglo XX; una de ellas tuvo como escenario la totalidad del mundo, ésta fue la Guerra Fría ${ }^{4}$. En este conflicto se enfrentaron ideológicamente dos bandos, Comunismo y Capitalismo, y los países que más sufrieron no solo fueron, como señalan algunos

1. Pontificia Universidad Javeriana.

ORCID: https://orcid.org/0000-0002-0830-6536

Google Académico: https://scholar.google.com/citations?hl=es\&user=Elc2AXOAAAAJ

2. Lecturas como: La Filosofía de la Liberación de E. Dussel y la Teología de la Liberación de G.Gutiérrez y L. Boff, las cuales tienen una cierta influencia sociológica de corte marxista. Hay que señalar además que, como lo menciona Adolfo Galeano, los planteamientos de Teología de la Liberación, de autores como Leonardo Boff, "No tienen sin embargo una fundamentación en el misterio cristiano" (Galeano, 2008, p.220).

3. La cual, se desarrolló en el Il ciclo de jornadas teológicas centroamericanas y caribeñas.

4. "Veinte años después de haber comenzado la Guerra Fría, la imagen de los años 1919-1939 como un paréntesis de paz apoyado en dos guerras mundiales, se convierte en algo cada vez más irreal. La guerra parece ser más endémica de la vida en la mitad del siglo XX de lo que esa imagen implica" Thompson, 1993, p. 247), lo que puede explicar la persistencia de los conflictos después de la guerra fría, al ser uno de los antecedentes del contexto actual. 
autores $^{5}$, los de Latinoamérica, sino los países que estaban bajo dominio e influencia Soviética, sin embargo no se pretende negar el sufrimiento social de Latinoamérica ${ }^{6}$. Este sufrimiento en cierta medida se vio causado por la urgente necesidad de garantizar la democracia en América Latina, pues de ningún modo se podría permitir que América Latina cayera en dominio soviético?.

En ese orden de ideas, los conflictos y levantamientos en mayor medida, denunciaban una crisis social, que no se puede atribuir solamente al dominio del Neoliberalismo y el Capitalismo de Estados Unidos, sino también, y con mayor razón al Comunismo de la Unión Soviética, que había logrado implantar la utopía de igualdad y con esto expropiar los recursos medianamente necesarios para convivir y subsistir en la sociedad. Si bien es cierto que mi realidad histórica está configurada por diversas interpretaciones, también lo está, con mayor razón, por los hechos y las fuentes que corroboran el sentido último de verdad ${ }^{8}$. Esto explica, sin más mediaciones, que el sufrimiento de las personas de mi realidad se debe por diferentes razones; pero es preciso aclarar que la categoría sufrimiento no se puede reducir sociológicamente a las relaciones político-económicas de los individuos ${ }^{9}$.

Ahora bien, aclarado el caso, si se hace referencia a las personas de mi realidad, que sufren las consecuencias de una guerra generada por conflictos interiores en la nación (Pérez, 2013), hay que precisar además que sobre el tema se ha escrito mucha literatura fantástica desde la sociología ${ }^{10}$, obviando el papel de la historia, sin embargo, como el tema

5. Iñigo (2011) señala que "La pobreza y la desesperación [en Europa] eran tan grandes en la inmediata posguerra que un triunfo comunista devenía más probable que nunca" (p.290).

\footnotetext{
6. Pues es preciso anotar que "Las grandes desigualdades sociales se profundizaron enormemente durante el siglo XX, hasta el punto en que algunos países de la región [llegaron a ostentar] los mayores índices de desigualdad en la distribución de la riqueza. (Gómez, 2010, p.289).
}

7. Ejemplo de ello es la conocida Doctrina Truman que aparece en los orígenes de la Guerra Fría. Según (Gómez, 2010) Centroamérica se mantuvo gran parte del siglo bajo la egida de las dictaduras sostenidas por los estados unidos, a las que se reaccionó violentamente con revoluciones comunistas apoyadas desde la lejana Unión Soviética, dentro del marco de la Guerra Fría" (p.288).

8. Algunas fuentes y hechos ya han sido enunciados, sin embargo, es oportuno mencionar un hecho como lo fue la creación del plan Marshall, que fue un programa de ayudas económicas, por parte de los Estados Unidos, para reconstruir a Europa luego de la Segunda Guerra Mundial, y de la alianza para el progreso, que se creó para ayudar económicamente a Latinoamérica, lo que apoya la tesis de que en cierta medida el neoliberalismo no es el causante de las crisis sociales de los países latinoamericanos como si lo puede ser el comunismo de la URSS.

9. Tal como se redujo la categoría "pobre" en la Teología de la Liberación de G. Gutiérrez, quien desplazó al pobre "desde el contexto eclesial al contexto marxista... [y] el término 'pobre' [se volvió] impreciso e intraeclesial, un poco sentimental y, finalmente, aséptico" (Galeano, 2008, pp.220-221).

10. Como por ejemplo la del sociólogo A. Molano, (2015) quien afirma, entre otras cosas, 
es el sufrimiento, visto desde la óptica de los autores, es preciso retomar, el camino señalado inicialmente.

Se pude partir reconociendo que el lenguaje teológico "tiene la capacidad de sacarnos de nosotros mismos para llevarnos al trascendente (Vélez, 2008, p. 35). Esto cobra sentido porque uno de los problemas que se pueden evidenciar en la Teología de la Liberación, la cual centra su objeto de estudio, en el pobre, el oprimido o el que sufre, es que hay un abandono del fundamento divino, que es comprendido como la realidad espiritual, al optar por las realidades terrenales (Azevedo,2014). En tal sentido las palabras: Pobre, oprimido y sufriente, se reducen al desfavorecido del contexto sociopolítico actual.

La Teología de la Liberación, como lo expresa (Galeano, 2008) ${ }^{11}$, no ve al pobre en el sentido de caridad y humildad, sino como el aparentemente oprimido, y es aparente porque que la concepción de opresión puede ser una falsa interpretación que solo lleva a la victimización en muchos aspectos de la sociedad; esto se ve por ejemplo con el eufemismo de "Afro descendencia", ya que no se puede decir que alguien es negro porque sería racismo, aunque no se ve que utilizar el concepto Afro descendiente conlleva al racismo y a la exclusión, y se llega a olvidar que todo ser humano proviene del África (Langer, 2016) ${ }^{12}$.

En la Teología Católica deben conjugarse los dos aspectos [Razón y fe] (Vélez, 2008, p.24). Esto implica que de alguna manera, el pobre no puede tener autoridad en la Teología si dicha autoridad no evoca en la fe, pues el sufriente es la fuente de testimonio que aporta al sentido trascendental de la fe. Se apela a este argumento en virtud de que la observación de situación actual de la realidad social, da como resultado que en muchos casos para tener algún reconocimiento en el mundo social, hay que ser víctima de alguna situación, sin importar que tal autoridad de lugar a concepciones falsas de la misma realidad (de Almeida, Santos \& Porto, 2016).

que "Laureano [Gómez], junto con Alzate y Avendaño y los leopardos, se asumieron como legítimos representantes del fascismo español y del nazismo alemán" (p.15), cuando la realidad es que el mismo Laureano fue quien expulsó a los Leopardos del Partido Conservador, y además tuvo una postura de rechazo frente a ideologías extremistas como las del fascismo y el nazismo, tal como se evidencia en textos como "El cuadrilátero" publicada en 1935, en la editorial centro; lo anterior hace incomprensible y confusa la realidad.

11. "El pobre, hoy, es el oprimido, el marginado por la sociedad, el proletario que lucha por sus más elementales derechos, la clase social explotada y despojada..." (Galeno, 2008, p. 221).

12. Lo cual podría ser una tesis que podría confrontar los planteamientos de algunas perspectivas de la Teología Negra. 
De acuerdo con lo anterior es oportuno mencionar que la Teología como Hermenéutica, lleva necesariamente a replantear el concepto mismo de Teología y su función explicitadora de la revelación (Suarez \& Noratto, 2007, p. 127), lo que implica que un enfoque hermenéutico permitiría reconocer en el sufriente un grado de verdad que se iluminaría con la revelación pues, Como lo señala, Vélez (2008), "la fe debe Iluminar el primer paso de mediación socio analítica y más cuando el instrumental de análisis es el marxismo, pues este promueve utopías distantes de la fe"

Se sabe además que la teología latinoamericana, "[tuvo]....preocupación por el pobre y explicitó así la dimensión social del quehacer teológico" (Vélez, 2005, pp. 35-36) y evidentemente el sufriente no tiene autoridad para determinar cómo debe ser la realidad, pero tiene autoridad para hablar de sus aflicciones sin apelar a las categorías de la dialéctica materialista de Marx, porque en este caso el sufrimiento tendría una clara intencionalidad política. Es así que como lo señala Vélez (2008) "En el fondo siempre existen fundamentos ideológicos para toda praxis" (p.216).

La autoridad del sufriente puede considerarse una categoría hermenéutica que conlleve a "nuevos caminos que ayuden a la comprensión de la revelación a partir de las sagradas escrituras, reconociendo la existencia de los creyentes y sus condiciones propias de vida" (Suarez \& Noratto, 2007), y tal vez configurar una mejor Teología, la Teología del sufrimiento, vista como el estudio a partir de la revelación de las aflicciones, no solo de los sufrientes de América Latina, sino del género humano que sufre en algún momento de la existencia (Ferreyra, 2014).

En conclusión, En primer lugar, para comprender la realidad actual y determinar verdaderamente quiénes y cuáles son los que sufren, es necesario remitirse a fuentes históricas, más que a las sociológicas. En segundo lugar, solo se puede determinar la autoridad del sufriente si primero se explicita y se aclara el sentido de sufrimiento, a partir de un acercamiento hermenéutico. En tercer lugar, el sufrimiento, al ser subjetivo no puede determinar la verdad, pero puede contribuir a una aproximación comprensiva de la misma. Por último, una Teología de la Liberación es genuina teología, con su trasfondo divino, si es iluminada en todo momento por la palabra de Dios, dando lugar a que la liberación se entienda como una superación y dominio del sufrimiento y no como el cambio de las estructuras sociales e implantación de un sistema socialista o en últimas circunstancias, comunista, ya que de ser así, no se estaría haciendo Teología sino Sociología. 


\section{Referencias bibliográficas}

Azevedo, S. R. J. (2014). La composición histórica de la educación religiosa como componente curricular. Revista Interamericana de Investigación, Educación y Pedagogía, RIIEP, 7(1). DOI: https://doi.org/10.15332/s1657-107X.2014.0001.03

de Almeida, R. R., Santos, M. F., \& Porto, J. C. (2016). Lectura de textos ficcionales y el enfoque escolar de literatura: contribuciones para una Pedagogía de la Elección. Revista Interamericana de Educación, Pedagogía y Estudios Culturales, 9(1), 35-51. DOI: https://doi.org/10.22490/25391887.1925

Ferreyra, H. A. (2014). Mesas Socioeducativas para la Inclusión y la Igualdad. Un programa "De todos con todos". Una experiencia en construcción. Revista Interamericana de Investigación, Educación y Pedagogía, RIIEP, 7(2). DOI: https://doi. org/10.15332/s1657-107X.2014.0002.01

Galeano, A. (2008). Tensiones y Conflictos de la Teología en su Historia. Bogotá: Ed. San Pablo.

Gómez, J. (2010). Historia de Iberoamérica: Una Historia de Grandes Contradicciones. En Hernández, J. Correa, H. \& Uribe, C. (Comps.) Historia de la Cultura en 20 lecciones. (pp. 267-290) Bogotá: Universidad Sergio Arboleda.

Gómez, L. (1935). El Cuadrilátero. Bogotá: Ed. Centro.

Íñigo, L. (2011). Breve Historia del Mundo. Madrid: Nowtilus.

Langer, E. (2016). La construcción de confianza para el estudio de prácticas de resistencia en la escolarización de jóvenes en contextos de pobreza urbana. Revista Interamericana de Investigación, Educación y Pedagogía, RIIEP, 9(2). DOI: https://doi. org/10.22490/25391887.1945

Molano, A. (2015). Fragmentos de la Historia del Conflicto Armado (1920-2010).

Recuperado de http://corteidh.or.cr/tablas/33246.pdf

Pérez, T. H. P. (2013). Aproximaciones al estado de la cuestión de la investigación en educación y derechos humanos. Revista Interamericana de Investigación, Educación y Pedagogía, RIIEP, 6(1). DOI: https://doi.org/10.15332/s1657-107X.2013.0001.05

Suarez, G. \& Noratto, J. (2007). La Racionalidad Hermenéutica en Teología. En Baena, G., Martínez, D., Martínez, V., Noratto, J., Suarez, G. Los Métodos en Teología (pp.103129). Bogotá: Ed. Universidad Javeriana.

Thompson, D. (1993) Historia Mundial de 1914 a 1968. Bogotá: Ed. Fondo de Cultura Económica. 
Vélez, O. (2008). Un nuevo paradigma Teológico. En Vélez, O. El Método Teológico. Fundamentos, especializaciones y enfoques. (pp. 17-61). Bogotá: Ed. Universidad Javeriana.

Vélez, O. (2008). Teologías de genitivo y nuevos enfoques teológicos. En Vélez, O. El Método Teológico. Fundamentos, especializaciones y enfoques. (pp. 163-222). Bogotá: Ed. Universidad Javeriana. 